\title{
COMMENTS SECTION
}

\section{Introduction: Commentaries on current research trends in recruitment studies}

\section{Howard I. Browman}

Department of Fisheries and Oceans Canada, Maurice-Lamontagne Institute, Division of Ocean Productivity, PO Box 1000, Mont-Joli. Quebec, Canada G5H 324

E-mail: h-browman@qc.dfo.ca

The 3 comments that follow were solicited shortly after the publication of William C. Leggett and Elizabeth $M$. DeBlois' contribution 'Recruitment in marine fishes: is it regulated by starvation and predation in the egg and larval stages', which appeared in the Netherlands Journal of Sea Research in 1994 (Vol. 32, p. 119-134). The goal was to obtain comments from researchers who have worked on recruitment issues but who have focussed on somewhat different specific questions at different levels of analysis. A response (further discussion, really) from Leggett and DeBlois follows.

Having solicited and collated this comments section, I permit myself the self-indulgence of putting in my own succint two cents' worth. The points that follow are presented in no particular order.

(1) A significant percentage of marine finfish larvae never initiate exogenous feeding. Why this might be so is unclear and it is rarely mentioned in the literature. Nonetheless, it is an observation that many who have cultured larvae can attest to and may also explain why field samples of fish larvae often contain large percentages with empty guts. The implications of this observation for field and laboratory studies of feeding and growth rate (which lead to predictions of recruitment for the year class) should not be ignored.

(2) A single solution to The Recruitment Question, one that is applicable to all or most species, is unlikely. The amount of effort invested in finding such a universal solution should be proportional to the probability that it exists.

(3) The current focus on microscale turbulence as a determining factor in ichthyoplankton-zooplankton encounter rates does not consider the following issues: (a) If both predator and prey are operating at low Reynolds numbers they will be entrained in the same microturbulent eddies. Under such conditions, it is unlikely that microturbulence will increase encounter rates. (b) Even if microturbulence does increase encounter rates, it may not increase ingestion rates. (c) It is difficult to determine from field studies that correlate larval gut loading indices and wind shear whether microturbulence was the direct (in a mechanistic sense) cause of the relationship. Detailed observations of the behavioural responses of larvae and their prey to turbulent fields are required to resolve these issues.

(4) In general, fisheries science is too proximate and mechanistic. More ultimate-level thinking could not hurt. For example, and following point (1): Why do highly fecund fishes produce such a high proportion of seemingly non-viable gametes? Or, why do batch spawners such as Atlantic cod produce egg batches of dramatically different quality?

(5) Discussion platforms such as this one can help us to clarify our thinking about these issues. I look forward to more of them.

\section{A comment on Leggett \& DeBlois}

\section{H. Cushing}

198 Yarmouth Road, Lowestoft, Suffolk NR32 4AB, United Kingdom

Leggett WC, DeBlois E (1994) Recruitment in marine fishes: is it regulated by starvation and predation in the egg and larval stages. Neth J Sea Res 32:119-134

At a meeting organized by the late Dr Reuben Lasker at La Jolla (CA, USA), there was much argument whether starvation or predation was the proximate cause of the variability of recruitment in fishes. With glee, I see that Leggett and DeBlois believe that we should examine the interaction between the two.

In their examination of the possible theses, they reject Johan Hjort's view that recruitment was determined at the time of first feeding because recent studies have shown that the magnitude of recruitment might be linked to the abundance of late larvae and not to that of the early larvae. Until fairly recently the late larvae were not sampled very well; for example, Bückmann (1942) caught herring larvae at the length of $40 \mathrm{~mm}$ with a Petersen Young Fish Trawl whereas some later gears could not catch larvae longer than $20 \mathrm{~mm}$.

The match/mismatch hypothesis is not only one of starvation. In Cushing (1990) I wrote that 'well fed larvae grow quickly and experience less predatory mortality than poorly fed ones'. Leggett and DeBlois 
note that the demonstration of a relationship between food level and survival is equivocal. It does not exist save in an imaginary sense (see the model in Cushing \& Horwood 1994). My former colleague, John Shepherd, used to say that the match/mismatch hypothesis was a truism, by which I think he meant that some such mechanism must exist. I once wrote a paper called 'Had I but world enough and time...' (Cushing 1985) in which I suggested that growth and mortality be measured from the time of first feeding to the time of recruitment. The reason for the coyness of fisheries scientists in attacking the problem is the cost of repeated surveys by research vessels.

The investigation of the relationship between food and feeding success is of considerable importance, particularly in the analysis and observation of turbulence. I believe that estimates at sea of $g / g_{\max }$ are desirable (where $g$ and $g_{\max }$ are specific growth rate and maximal specific growth rate, respectively). When I wrote of the links between upwelling and recruitment, I was really discussing the inverse relationship between them attributed to Ekman transport. I now believe that because the bulk of the larvae off Southern California live far outside the Sverdrup boundary to coastal upwelling, Ekman transport does not explain the inverse relationship.

The study of predation at sea is difficult, but the experimental work in mesocosms and in theoretical studies is to be commended. A review by Fuiman \& Margurran (1994) is of great value. They described the vulnerability to a predator as a compound of 3 probabilities, encounter, attack and capture, which formed a dome shaped curve in prey length as estimated from mesocosm experiments. The 'bigger is better' and the stage duration hypotheses are really both founded on incomplete views of the process of feeding and predation.

Prof. Leggett and Dr DeBlois conclude that the 'either/or' approach of food may be indirect and may operate principally through its regulation of the timing and intensity of mortality due to predation. This is almost a statement of the match/mismatch hypothesis in which differences in timing from year to year may generate differences in the degree of predation (with the Cushing \& Horwood model referred to above). Both views, if a little different, are vulnerable to changes from year to year in timing, as for example differences in wind direction in Bryant's Cove, where Leggett and his colleagues worked in Newfoundland.

An enormous amount of work has been carried out on the problem of recruitment. Prof. Leggett has done more than anyone else to expose the putative mechanisms that may govern the origin of recruitment. I hope that he won't take it amiss if I say that despite the labours of lots of people and his incisive insights, the science of recruitment does not yet exist.

\section{LITERATURE CITED}

Bückmann A (1942) Die Untersuchungen der Biologischen Anstalt über die Ökologie der Heringsbrut in der südlichen Nordsee. Helgoländer wiss Meeresunters 3: $1-17$

Cushing DH (1985) Had I but world enough and time... Comm Meet Int Coun Explor Sea ICES CM 1985/H:71

Cushing DH (1990) Plankton production and year class strength in fish populations: an update of the Match/Mismatch Hypothesis. Adv mar Biol 26:249-293

Cushing DH, Horwood JW (1994) The growth and death of fish larvae. J Plankton Res 16:291-300

Fuiman LA, Margurran AE (1994) Development of predator defences in fishes. Rev Fish Biol Fish 4:145-183

\section{The 'critical period' concept - a century of recruitment research}

\author{
Bjornar Ellertsen*, Petter Fossum, Per Solemdal, \\ Svein Sundby \\ Institute of Marine Research, PO Box 1870 Nordnes, \\ N-5024 Bergen, Norway \\ - E-mall bjoernar.ellertsen@imr.no
}

The paper 'Recruitment in marine fishes: is it regulated by starvation and predation in the egg and larval stages' by Leggett \& DeBlois (1994) is an excellent, neutral attempt to evaluate the main ideas in recruitment thinking of this century. We fully agree with the authors' main conclusions that the importance of starvation and predation in early-life mortality remains unsolved, that the situation may vary with species, area and year, and that the idea that recruitment is not regulated by starvation and predation in early stages is not justified at this time.

The present confused situation could be the result of an orthodox attitude to the 'classical' ideas. For some time now, the mainstream schools on both sides of the argument (starvation, predation) have been fighting each other, becoming more and more 1-dimensional.

The most important reason for the present state of this debate is the complexity of the problem itself. Johan Hjort, the 'inventor' of year-class variations, was well aware of the complex nature of the causes of these variations when he launched his simple idea of the critical stage, just to focus on a logical starting point The Hjort 'critical stage' idea and D. H. Cushing's match/mismatch idea are both based on the varying synchrony of the larval hatching process and the occurrence of prey, driven by interannual and longterm environmental variations. 
The initial working hypothesis of the Norwegian Cod Larvae Projects 1975-1984 was that mortality during Hjort's 'critical period' (the first-feeding stage) was strongly influencing year-class strength (Ellertsen et al. 1989). We never succeeded in showing that a critical period determining the year-class strength was limited to this rather short period of time. This was partly due to the difficulties in assessing larval mortality when surveying a very dynamic system where mortality during first feeding and immediately afterwards was very high and rapidly changing, and to the fact that small changes in growth and mortality over a longer period of time can have equal or even more dramatic effects on year-class strength.

An example of year-class strengths being determined at a much later stage was described for the Barents Sea in the mid 1980s. The originally strong yearclasses of Northeast Arctic cod at the 0-group stage were reduced to moderate or weak year-classes at the age of 3 yr, due to a collapse of the capelin stock resulting in strong cannibalism within the cod stock. Such events indicate that the year-class strength is a result of accumulated recruitment events over a longer period of time, influenced by a number of variable biotic and abiotic parameters.

Recent investigations indicate that recruitment has multiple causes. No single factor seems to explain year-class levels. Ellertsen et al. (1989) indicated that even though temperature-dependent nauplii production supports the match/mismatch hypothesis, temperature alone cannot explain year-class strength. Two factors will affect the output of the classical HjortCushing idea: the turbulence-induced contact rate between fish Iarvae and their prey, and the maternal factor affecting size of larvae at hatching, throughout the season and interannually. By taking these relations into account a more realistic evaluation of the HjortCushing idea would be possible.

The effect of turbulence on encounter rates has been put forward as an explanation for the lack of a simple relation between larval feeding and prey concentration. The present group was the first to investigate the effect of small-scale turbulence on plankton contact rates and fish larvae feeding in the field (Sundby \& Fossum 1990). The positive effect of wind speed continues to increase up to at least $15 \mathrm{~m} \mathrm{~s}^{-1}$ for first-feeding larvae (MacKenzie et al. 1994, Sundby et al. 1994).

Neither Hjort nor Cushing included the maternal effects in their ideas. Leggett \& DeBlois also omitted discussing a factor which has gained increasing interest in recent years - the effect of parental condition on larval survival. The eggs spawned in consecutive batches by an individual Arctic Norwegian cod will decrease in size throughout the spawning season, as will the larvae hatching from these eggs. There is also a positive correlation between cod size and the size of eggs spawned. As a result of the annually varying synchrony between the hatching of larvae and the production of their prey, the larger larvae that hatch first will encounter the best prey situation in warm years. First-time spawners produce smaller larvae over a relatively short period, while the longer spawning period in large fish reduces the problem of synchrony. Consequently, maternal effects on recruitment should be taken into consideration (Ellertsen \& Solemdal 1990). This idea supports the concept of 'bigger is better'.

The time of uni-dimensional recruitment investigations has come to an end. We should acknowledge that recruitment occurs as a part of ecosystem dynamics comprising a multi-dimensional system. Experiments involving a restricted number of recruitment factors should be designed for lab and mesocosm. Correlative studies in recruitment research need to be pursued by investigating the individual basic processes involved. Conceptual models are important for the discussion of recruitment processes, but they have little value for testing recruitment hypotheses.

We need to quantify the basic physical as well as biological processes behind growth and mortality and the functional relationships between them in order to understand recruitment. Recent aquaculture research on mass rearing of marine fish from the egg stage demonstrates how important it is, when quantifying basic processes, to utilise results from disciplines other than traditional recruitment research. The effects of the various basic processes on growth and survival of individuals must be quantitatively integrated into numerical circulation models in order to calculate growth and survival on the population level and hence simulate year-class strength.

\section{LITERATURE CITED}

Ellertsen B, Fossum P, Solemdal P, Sundby S (1989) Relations between temperature and survival of eggs and first feeding larvae of the northeast Arctic cod (Gadus morhua L.). Rapp P-v Réun Cons int Explor Mer 191:209-219

Ellertsen B, Solemdal P (1990) Spawning strategy and a mechanism for adaptive larval production in ArctoNorwegian cod. Comm Meet lnt Coun Explor Sea ICES CM 1990/L:100

Leggett WC, DeBlois E (1994) Recruitment in marine fishes: is it regulated by starvation and predation in the egg and larval stages. Neth J Sea Res 32:119-134

Mackenzie BR, Miller TJ, Cyr S, Leggett WC (1994) Evidence for a dome-shaped relationship between turbulence and larval fish ingestion rates. Limnol Oceanogr 39(8):1790-1799

Sundby S, Ellertsen B, Fossum P (1994) Encounter rates between first-feeding cod larvae and their prey during moderate to strong turbulent mixing. ICES mar Sci Symp 198:393-405 
Sundby S, Fossum P (1990) Feeding conditions of Arcto-Norwegian cod larvae compared to the Rothschild-Osborn theory on small-scale turbulence and plankton contact rates. J Plankton Res 12(6):1153-1162

\section{Recruitment of marine fish: the relative roles of density-dependent and density- independent mortality in the egg, larval, and juvenile stages}

\author{
Ransom A. Myers \\ Northwest Atlantic Fisheries Centre, Science Branch, PO Box 5667, \\ St. John's, Newioundland, Canada A1C $5 \times 1$ \\ E-mail:myers@mrspock.nwafc.nf.ca
}

In their excellent review of recruitment in marine fish, Leggett \& DeBlois (1994) attempt to synthesize the vast amount of literature that has been produced over the last $80 \mathrm{yr}$. The enormity of this task lies in the fact that there are many studies that have yielded inconsistent results, because many processes are operating and the power of many tests is very low. The crux of the recruitment problem is to determine the magnitude and cause of density-dependent and densityindependent components of mortality during the egg, larval, and juvenile stages. Some progress has been made. Leggett \& DeBlois conclude that the primary source of variability in recruitment is the enormous interannual variability in density-independent mortality during the egg and larval stages. However, they were unable to identify the source of the interannual variability in density-independent mortality. I suggest that the following points are crucial for further progress.

(1) There is a need for meta-analysis. When studies are being reviewed it is often examined how often an effect is statistically significant. This can be a very misleading approach, even though it is intuitively appealing. For example, if the reviewer simply examines how often an outcome is statistically significant, then there will be a strong bias towards the conclusion that the process or treatment has no effect (Hedges \& Olkin 1985). Furthermore, this bias is not reduced as the number of studies increases. If a large number of studies or populations are examined, the proportion of studies that yield statistically significant results is approximately the average power of the test used (Hedges \& Olkin 1985). That is, a reviewer of research studies may assume that he is examining the importance of an ecological process, but may only be examining the power of the tests used to examine it. Research synthesis without considering the statistical problems can lead to serious mistakes. I believe that
Leggett \& DeBlois were mistaken in expecting 'definitive studies'.

(2) Work should focus on obtaining quantitative estimates of the components of density-independent mortality that can be attributed to different causes, e.g. starvation, predation, and advection, and quantitative estimates of density-dependent mortality at different stages.

(3) Error in estimating abundance imposes fundamental limitations on the kinds of questions that can be addressed. For demersal fish, it is possible to estimate the density-dependent and density-independent component of mortality between the egg and demersal stages, or within the demersal stage. However, reliable estimates of the sources of variability within the egg and larval stages are almost impossible except for a very few species and using enormous sampling effort, e.g. the California Cooperative Oceanic Fisheries Investigation (CalCOFI).

(4) Results should be presented in such a way that they can be compared among populations and species. The components of the interannual variability in mortality can be compared among populations and species (Myers 1995). Similarly, if mortality is proportional to log density, then the coefficient of density dependence can be compared across populations, which is assumed in key factor analysis in the analysis of insect populations (Myers \& Cadigan 1993)

(5) Very few studies reviewed by Leggett \& DeBlois are taken beyond the interpretive stage, in the sense that they claim only that observations are consistent with a hypothesis, without ever fully testing the hypothesis. That is, the statistical power of an analysis is not addressed before the study is undertaken.

(6) Advection may be more important than biological processes, e.g. despite the extensive plankton records in the North Sea from the Continuous Plankton Recorder, Brander (1992) was unable to find any link with cod recruitment.

(7) There is a need for quantitative theories. Most of the theories discussed by Leggett \& DeBlois are conceptual rather than quantitative. There is a clear need for quantitative theories of recruitment that make falsifiable predictions. For example, Mertz \& Myers (1994) recently developed a model of D. H. Cushing's match/ mismatch theory that predicted that recruitment variability should increase as spawning duration decreases, a prediction that was supported by an analysis of Atlantic cod, Gadus morhua, data.

In conclusion, the next major review of recruitment studies should use formal meta-analysis. The difficulties of estimating egg and larval mortality should be recognized, because these impose fundamental limitations on the type of questions that can be addressed in recruitment studies 
Acknowledgements. 1 thank G. Mertz and P. Pepin for comments on the manuscript.

\section{LITERATURE CITED}

Brander K (1992) A re-examination of the relationship between cod recruitment and Calanus finmarchicus in the North Sea. ICES mar Sci Symp 195:393-401.

Hedges LV, Olkin I (1985) Statistical methods for metaanalysis. Academic Press, San Diego

Leggett WC, DeBlois E (1994) Recruitment in marine fishes: is it regulated by starvation and predation in the egg and larval stages. Neth J Sea Res 32:119-134

Mertz G, Myers RA (1994) Match/mismatch predictions of spawning duration versus recruitment variability. Fish Oceanogr 4:236-245

Myers RA (1995) The role of meta-analysis in the study of recruitment of marine fish. In: Chambers RC, Trippel EA (eds) Early life-history and recruitment of fish populations. Chapman and Hall, London (in press)

Myers RA, Cadigan NG (1993) Density-dependent juvenile mortality in marine demersal fish. Can J Fish Aquat Sci $50: 1576-1590$

\section{Researching recruitment - where to now?}

\section{W. C. Leggett ${ }^{1, \bullet}$, E. M. DeBlois ${ }^{2}$} 'Department of Biology, Queen's University, Kingston, Ontario,
Canada K7L 3N6

${ }^{2}$ Fisheries and Oceans Canada, Northwest Atlantic Fisheries Centre, While HIlls, St. John's, Newfoundland, Canada A1C 5X1

-E.mail:wcl@post.queensu.ca

We wish to begin our response to the foregoing comments of Dr Cushing, Drs Ellertsen, Fossum, Solemdal and Sunby, and Dr Myers on our paper 'Recruitment in marine fishes: is it regulated by starvation and predation in the egg and larval stages' (Leggett \& DeBlois 1994) with a word of praise to the editors of Marine Ecology Progress Series for their initiative in instituting this commentary series. Informed dialogue is the very essence of science. We look forward to the growth of this new feature, and are honoured to have had our paper identified for commentary.

It is clear from Dr Cushing's comments that we are in fundamental agreement on many issues. In particular we were pleased to note his agreement that debates and studies focused on the primacy of food vs predation as the regulator of survival in larval fishes have consumed too much time. Indeed the research community's fixation on particular hypotheses regarding the ultimate regulator (critical period, match/mismatch, bigger is better, starvation, predation) has, we believe, inhibited the development of a more synthetic understanding of these processes. It is time to explore new ideas. We wish to be clear that the above comments should not be interpreted as a call for the abandonment of the study of existing and emerging hypotheses. Many have merit and their continued investigation will yield useful insights. Future studies should, however, be designed to critically evaluate, rather than to champion, the hypothesis in question.

We are pleased to see that Ellertsen et al. also subscribe to this view. Their suggestion that more emphasis should be put on understanding the basic processes rather than trying to understand recruitment in one big jump has been the cornerstone of our work with capelin, and more recently with cod.

We are pleased, too, that Ellertsen et al. highlighted the potential importance of maternal effects on larval size and survival. They have reviewed their own work in this field. Other studies of maternal effects (Tanasichuk \& Ware 1987. Chambers et al. 1989, Chambers \& Leggett in press) also speak to this potential. Here too, however, it is important that the potential for maternal influences (i.e. well-nourished females produce larger eggs which in turn produce larger and better-nourished larvae) not be uncritically linked to higher offspring survival to the end of the larval period. In particular, the tendency to uncritically equate such effects with support for the 'bigger is better' hypothesis must be avoided. What these studies show is that maternal effects can enhance the variability in the size and nutrition of the larval population. The influence of this variation on survival and year-class formation remains an open question and is the focus of much of our own research at the present time.

Dr Myers finds our review conceptual rather than quantitative and strongly advocates the use of metaanalysis in future literature studies. Meta-analysis provides a methodology for combining findings from repeated research studies and provides a strong test of conformity and effect size across studies. We also advocate its use in quantitative reviews. Regrettably, comparable variates relating to larval fish survival and recruitment are scarce (but see MacKenzie et al. 1990, Bradford 1992, Myers \& Cadigan 1993a, b). In fact one of the most serious obstacles to a quantitative summary of the current state of affairs in recruitment research is the lack of consensus on how to gather and present data. We stress however that a 'general model' of recruitment may not be forthcoming since the combined effect of interacting factors affecting recruitment is likely to vary among systems.

The main bias associated with a 'vote counting' exercise such as the one employed in our review is that it fails to detect small effects while underestimating the importance of others (Hedges \& Olkin 1985). This may be why we find no firm evidence in support of Hjort's 
critical period, and limited support for Cushing's match/mismatch hypotheses (although these conceptual models are not readily falsifiable). It is important to note, however, that we did find consistent results in a number of instances (see Leggett \& DeBlois 1994). Overall, Myers provides an objective and balanced critique of our paper. A greater focus on quantitative theories and more effort toward homogeneity in the presentation of research findings are indeed imperative to the advancement of recruitment science, as is a more effective synthesis of what we already know.

\section{LITERATURE CITED}

Bradford MJ (1992) Precision of recruitment predictions from early life stages of marine fishes. Fish Bull US 90:438-453

Chambers RC, Leggett WC (in press) Maternal influences on variation in egg sizes in temperate marine fishes. Am Zool

Chambers RC, Leggett WC, Brown JA (1989) Egg size, female effects and the correlations between early life history traits of capelin (Mallotus villosus): an appraisal at the individual level. Fish Bull US 87(3):515-523

Hedges IV, Olkin I (1985) Statistical methods for meta-analysis. Academic Press, San Diego

Leggett WC, DeBlois E (1994) Recruitment in marine fishes: is it regulated by starvation and predation in the egg and larval stages. Neth J Sea Res 32:119-134

MacKenzie BR, Leggett WC, Peters RH (1990) Estimating larval fish ingestion rates: can laboratory derived values be reliably extrapolated to the wild? Mar Ecol Prog Ser 67:209-225

Myers RA, Cadigan NG (1993a) Density-dependent juvenile mortality in marine demersal fish. Can J Fish Aquat Sci 50:1576-1590

Myers RA, Cadigan NG (1993b) Is juvenile natural mortality in marine demersal fish variable? Can J Fish Aquat Sci 50:1591-1598

Tanasichuk RW, Ware DM (1987) Influence of interannual variations in winter sea temperature on fecundity and egg size in Pacific herring (Clupea harengus pallasi). Can J Fish Aquat Sci 45:1485-1495 